\title{
Tinjauan Ulang Terhadap Pondasi Tiang Bor Pada Pembangunan Gedung Mahasiswa Universitas Islam Riau Dengan Metode Elemen Hingga 2D Aksisimetri
}

\author{
Review of the Foundation of Bored Pile in the Construction of the Student Building of the \\ Islamic University of Riau by the Method of Finite 2D Axisymmetry
}

\author{
Dicky Nanda P. ${ }^{1}$, Anas Puri ${ }^{2}$, Sri Hartati Dewi ${ }^{2}$ \\ ${ }^{1}$ Mahasiswa Program Studi Teknik Sipil, Universitas Islam Riau \\ ${ }^{2}$ Pengajar Program Studi Teknik Sipil, Universitas Islam Riau \\ anaspuri@eng.uir.ac.id \\ srihartatidewi@eng.uir.ac.id
}

\begin{abstract}
Abstrak
Pembangunan gedung mahasiswa pada kawasan Universitas Islam Riau merupakan bangunan bertingkat 4 yang berfungsi sebagai tempat sekretariat organisasikemahasiswaan, kondisi tanah pada lokasi pembangunanGedung Mahasiswa pada Kawasan Universitas Islam Riaudidapat pada titik sondir 1 pada yaitu sebesar $50 \mathrm{~kg} / \mathrm{cm}^{2}$ Sedangkan pada titik sondir 2 yaitu sebesar $100 \mathrm{~kg} / \mathrm{cm}^{2}$. Penelitian ini merumuskan masalah apakah daya dukung tiang bor (bored pile) pada bangunan gedung mahasiswa Kawasan Universitas Islam Riau aman terhadap beban aksial, beban lateral dan momen dengan memperhitungkan beban mati, beban hidup, beban angin dan beban gempa, serta Berapa besar penurunan dan defleksi horizontal yang terjadi dengan menggunakan bantuan software ETABS v.9, menghitung kuat dukung, penurunan dan defleksi horizontal dengan metode elemen hingga menggunakan PLAXIS 2D.

Pembangunan gedung mahasiswa dikawasan Universitas Islam Riau Pekanbaru yang berlokasi dijalan Kaharuddin Nasution No.113 Marpoyan Damai-Pekanbaru Riau. Parameter tanah menggunakan data uji sondir dengan kedalaman pondasi $12 \mathrm{~m}$ dan diameter $30 \mathrm{~cm}$, Metode yang digunakan pada penelitian ini sesuai dengan tujuan penelitian dalam perhitungan daya dukung pondasi bored pile dan perpindahan yang terjadi dengan metode elemen hingga menggunakan PLAXIS 2D.

Hasil perhitungan memperlihatkan bahwa kapasitas daya dukung aksial pada titik sondir 1 yaitu sebesar 323,072 $\mathrm{kN}$ dan kapasitas daya dukung aksial pada titik sondir 2 yaitu sebesar $432,823 \mathrm{kN}$ sedangkan untuk daya dukung lateral pada titik sondir 1 didapat yaitu sebesar $125,016 \mathrm{kN}$, pada titik sondir 2 yaitu sebesar $190,703 \mathrm{kN}$ dan penurunan pada titik sondir 1 yaitu 40,04 mm dan pada titik sondir 2 yaitu 25,69 mm sedangkan untuk defleksi horizontal pada titik sondir 1 yaitu $10,91 \mathrm{~mm}$ dan pada titik sondir 2 yaitu $6,81 \mathrm{~mm}$. jadi defleksi horizontal yang terjadi pada titik sondir 1 dan 2 belum memenuhi syarat yang di ijinkan.
\end{abstract}

Kata kunci :bored pile, kuat dukung, penurunan, PLAXIS 2D.

\begin{abstract}
Building construction students in the region Riau Islamic University is a 4-storey building that serves as the secretariat of the student organization, the soil conditions at the construction site building Students in Region Riau Islamic University in the can at the point sondir 1 that is equal to $50 \mathrm{~kg} / \mathrm{cm} 2$, while at the point sondir 2 that is equal to $100 \mathrm{~kg} / \mathrm{cm} 2$. This study formulates the issue of whether the carrying capacity of pile (bored pile) on building student Region Riau Islamic University secured against axial loads, lateral loads and moments by calculating dead loads, live loads, wind loads and earthquake loads, as well as How big decline and deflection horizontal happens with the help of software ETABS v.9, powerful compute capacity, decline and horizontal deflection with the finite element method using PLAXIS $2 D$.

Student building area of Pekanbaru Riau Islamic University which is located 113 road Kaharuddin Nasution Marpoyan Peace-Pekanbaru Riau. Soil parameters using test data sondir the foundation depth of $12 \mathrm{~m}$ and a diameter of $30 \mathrm{~cm}$, method used in this study according to the research objectives in the calculation of the carrying capacity of bored pile foundation and displacement that occurs with the finite element method using PLAXIS 2D.

The calculation result shows that the carrying capacity of axial at point sondir 1 that is equal to $323.072 \mathrm{kN}$ and the carrying capacity of axial at point sondir 2 is equal to $432.823 \mathrm{kN}$ while for the lateral bearing capacity at the point sondir 1 obtained in the amount of $125.016 \mathrm{kN}$, at the point sondir 2 is equal $190.703 \mathrm{kN}$ and a drop in sondir point 1 is $40.04 \mathrm{~mm}$ and the sondir point 2 is $25.69 \mathrm{~mm}$ while the horizontal deflection at the point sondir
\end{abstract}


1 is $10.91 \mathrm{~mm}$ and the sondir point 2 is $6.81 \mathrm{~mm}$. so the horizontal deflection that occurs at the point sondir 1 and 2 are not yet qualified are allowed.

Keywords: bored pile, strong support, displacement, PLAXIS 2D

\section{PENDAHULUAN}

Pondasi adalah bagian dari suatu sistem rekayasa yang menopang beban dan meneruskan beban serta beratnya sendiri kedalam tanah dan batuan yang terletak dibawahnya (Bowles, 1997).

Pembangunan Gedung Mahasiswa Pada Kawasan Universitas Islam Riau merupakan bangunan bertingkat 4 yang berfungsi sebagai tempat sekretariat organisasi kemahasiswaan. Untuk meneruskan beban dari bagian struktur atas ke lapisan tanah di bawah hingga mencapai daya dukung yang diinginkan, maka perlu suatu bagian struktur bangunan bawah atau pondasi.

Kondisi tanah pada lokasi pembangunan Gedung Mahasiswa pada Kawasan Universitas Islam Riau di dapat pada titik sondir 1 pada kedalaman $12 \mathrm{~m}$ yaitu sebesar $50 \mathrm{~kg} / \mathrm{cm}^{2}$ di mana di dalam nilai qc termasuk dalam kategori tanah sangat kenyal, Sedangkan pada titik sondir 2 pada kedalaman $12 \mathrm{~m}$ yaitu sebesar $100 \mathrm{~kg} / \mathrm{cm}^{2}$ di mana di dalam nilai qc termasuk dalam kategori tanah keras, dari analisa tanah yang dilakukan dapat di lihat bahwa pondasi bored pile yang di gunakan terhadap titik sondir 2 dengan kondisi tanah yang keras akan mampu menerima beban yang bekerja pada pondasi, namun diperlukan analisa lebih lanjut untuk mengetahui kemampuan pondasi bored pile yang digunakan terhadap titik sondir 1 dengan kondisi tanah yang sangat kenyal.Di mana perencana, merencanakan jenis pondasi dan jumlah bored pile yang sama pada semua titik pondasi, sebelumnya telah dianalisa oleh Deni, 2015 tetapi analisa yang dilakukan deni tidak cukup lengkap untuk mengetahui kemampuan bored pile pada titiksondir1karena tidak memperhitungkan gaya lateral, pentingnya stabilitas dan kemampuan suatu struktur bangunan untuk menahan gaya lateral baik disebabkan oleh angin maupun gempa bumi, untuk itu perlu dilakukannya analisa ulang yang lebih lengkap terhadap pondasi pada Gedung Mahasiswa Universitas Islam RiauPekanbaru.

\section{Tujuan penelitian}

Tujuan yang akan dicapai dalam penilitian yang dilakukan adalah:

1. Menentukan besar daya dukung pondasi tiang bor (bored pile) tunggal, berguna untuk mengetahui apakah pondasi kuat dan aman terhadap beban aksial, beban lateral dan momen.

2. Menentukan penurunan dan defleksi horizontal yang dialami oleh pondasi tiang bor (bored pile) tunggal pada bangunan Gedung Mahasiswa kawasan Universitas Islam Riau, agar mengetahui apakah pondasi aman terhadap batas penurunan dan defleksi horizontal yang diizinkan.

\section{Manfaat penelitian}

Manfaat penelitian Tugas Akhir ini adalah :

1. Bagi pelaku pekerja konstruksi penelitian ini dapat menambah wawasan dan ilmu pengetahuan mengenai pondasi dalam, terutama tentang pondasi tiang bor (bored pile) serta mengetahui perhitungan daya dukung tiang bor.

2. Bagi mahasiswa yang masih menuntut ilmu di bangku perkuliahan dan pihakpihak yang bekepentingan, dapat menjadikan skripsi ini sebagai bahan refrensi dalam melakukan penelitian yang sama untuk masa yang akan datang.

3. Berdasarkan tinjauan yang ada dan perhitungan yang lebih lengkap penelitian ini dapat dijadikan sebagai acuan yang lebih komprehensif.

4. Skripsi ini dapat bermanfaat untuk Universitas Islam Riau sebagai perbandingan dengan perhitungan yang sudah di rencanakan. 


\section{LANDASAN TEORI Pondasi Tiang Bor}

Tiang bor dipasangkan dalam tanah dengan cara mengebor tanah terlebih dahulu, baru kemudian diisi tulangan dan di cor beton. Tiang ini biasanya, dipakai pada tanah yang stabil, sehingga memungkinkan untuk membentuk lubang yang stabil dengan alat bor. Jika

Ada beberapa jenis tiang bor yaitu :

1. Tiang bor lurus untuk tanah keras.

2. Tiang bor yang ujungnya diperbesar berbentuk bel.

3. Tiang bor yang ujungnya diperbesar berbentuk trapesium.

Tiang bor lurus untuk tanah batu-batuan.

Berikut gambar jenis tiang bor di atas sebagai berikut:

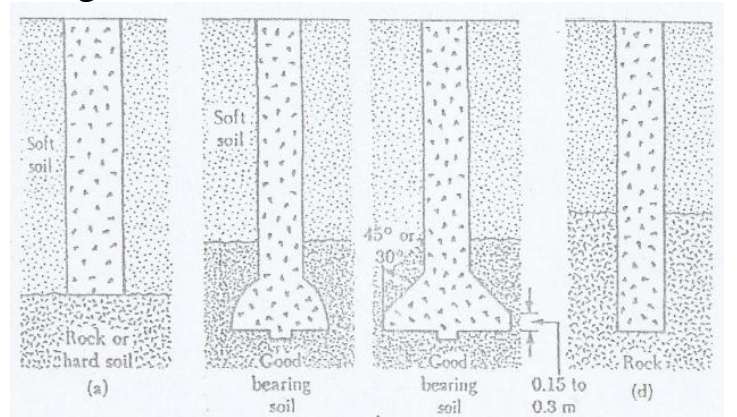

Gambar 1.1 Jenis-jenis tiang bor (Das, 1941 dalam Girsang, 2009)

\section{Uji Penetrasi Kerucut Statis}

Uji penetrasi kerucut statis atau uji sondir banyak digunakan di indonesia disamping uji SPT. Pada tanah dasar pasir yang tidak efektif, karena mengalami kesulitan dalam menembus tanah. Nilai nilai tahanan kerucut statis atau tahanan konus $(q c)$ yang diperoleh pengujian, dapat dikorelasikan secara langsung dengan kapasitas dukung tanah dan penurunan pada pondasi-pondasi dangkal dan pondasi tiang.

Pembacaan tahanan kerucut statis atau tahanan konus dilakukan melihat arloji pengukur, nilai qc adalah besarnya tahanan dibagi dengan luas penampang. Pembacaan arloji pengukur, di lakukan pada tiap-tiap penetrasi selama $20 \mathrm{~cm}$. Tahanan ujung serta tahanan gesek selimut alat sondir kerucut statis atau tahanan konus yang menyajikan nilai keduanya dapat di lihat pada gambar 3.6 (Hardiyatmo, 2006:63).

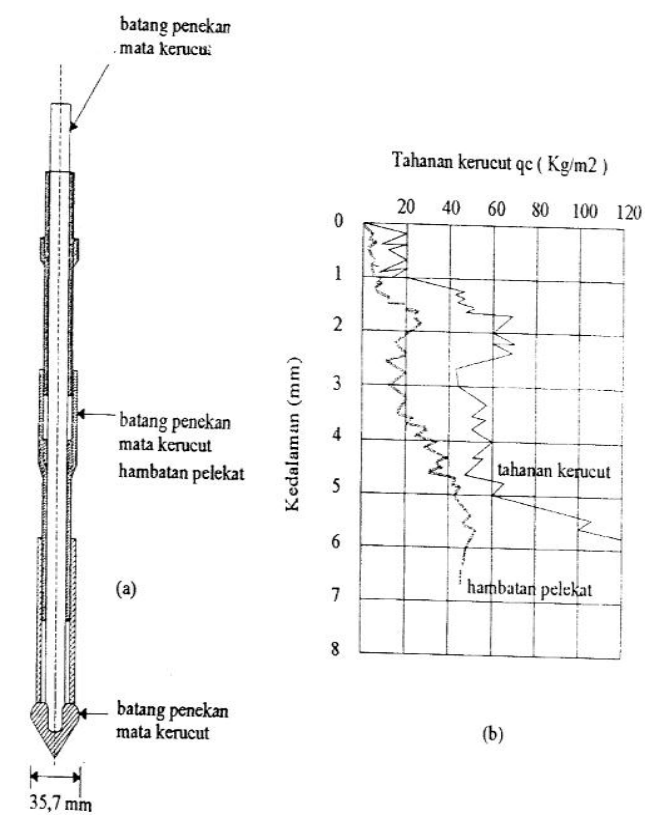

Gambar 1.2 Uji Kerucut Statis

(Hardiyatmo, 2002)

Karena uji kerucut statis (sondir) tidak mengeluarkan tanah saat pengujian berlangsung, maka jenis tanah tidak dapat diketahui dengan pasti, Robertson dan Campanella (1983) mengusulkan hubungan tahanan konus $(q c)$ dengan rasio gesekan Rf, untuk mengklasifikasi tanah secara pendekatan, seperti yang ditunjukkan dalam gambar 3.3 b. Pada gambar tersebut Rf Adalah Rasio Gesekkan (friction ratio) yang merupakan perbandingan anatara gesekan selimut local, fs (gaya gesek yang bekerja pada selimut konus dibagi dengan luas selimutnya atau disebut gesek satuan) dengan tahanan konus $q c$ atau rasio gesekkan (Hardiyatmo, 2006:63).

\section{Parameter Tanah}

\section{Sistem Klasifikasi Tanah}

Data cone penetration test (CPT) atau sondir dapat digunakan untuk memperkirakan klasifikasi tanah dalam rentang dimana pengujian tersebut dapat diterapkan.

Robertson dan Campanella secara khusus mengusulkan hubungan antara tahanan ujung dengan hambatan setempat 
yang dipakai untuk menghitung rasio gesekan $(f r)$ sebagai berikut:

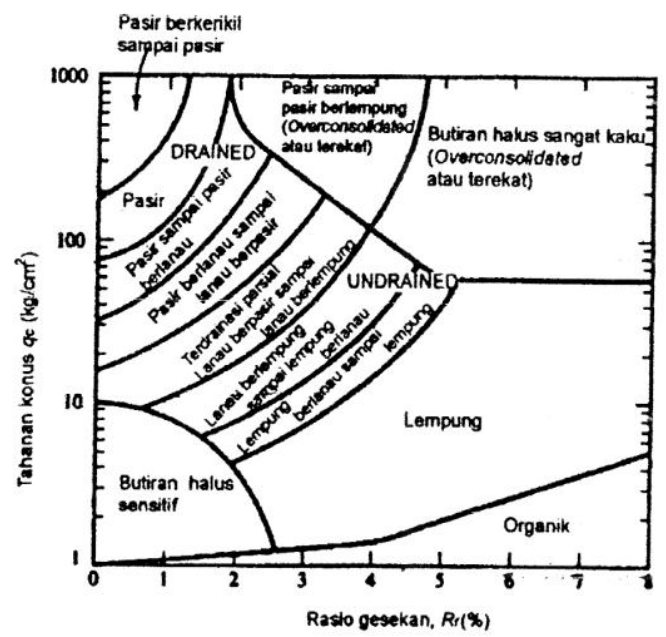

Gambar 1.3 Kelas. Tanah (Robertson dan Campanella, 1983 dalam Deny, 2015)

$F r=\frac{q s}{q c} \times 100 \%$

Keterangan :

qs = hambatan setempat $\left(\mathrm{kg} / \mathrm{cm}^{2}\right)$

$\mathrm{qc} \quad=$ perlawanan konus $\left(\mathrm{kg} / \mathrm{cm}^{2}\right)$

Pasir biasanya mempunyai rasio gesekan $f_{r}<1 \%$. Rasio gesekan lempung lebih besar dan gembut dapat mempunyai $f r>5$ atau $6 \%$. Pada gambar 3.5 dapat dilihat klasifikasi tanah yang ditentukan dengan rasio gesekan fr (menurut Robertson dan Campanella,1983).

\section{Modulus Young}

Nilai modulus young merupakan besarnya nilai elasitisitas tanah yanh merupakan perbandingan antara tegangan yang terjadi terhadap regangan. Rumus umum untuk menentukan modulus young berdasarkan data CPT.

Untuk tanah pasir sebagai berikut:

$E=2 . q c\left(\mathrm{~kg} / \mathrm{cm}^{2}\right)$.

Untuk tanah lempung sebagai berikut:

$E=2$ sampai 8 qc (lempung)......(3.3)

Keterangan:

$\mathrm{E} \quad=$ modulus young $\left(\mathrm{kg} / \mathrm{cm}^{2}\right)$

$\mathrm{qc} \quad=$ tahan ujung konus $\left(\mathrm{kg} / \mathrm{cm}^{2}\right)$
Tabel 1.1 Hubungan Es Dengan Qc (Das, 1995)

\begin{tabular}{|c|c|c|}
\hline No & Jenis Tanah & CPT $\left(\mathbf{K g} / \mathbf{c m}^{2}\right)$ \\
\hline $\mathbf{a}$ & $\mathbf{b}$ & $\mathbf{c}$ \\
\hline 1 & $\begin{array}{c}\text { Pasir } \\
\text { terkondolisasi } \\
\text { normal }\end{array}$ & $E_{S}=(2-4) q c$ \\
\hline 2 & $\begin{array}{c}\text { Pasir } \text { over } \\
\text { konsolidasi }\end{array}$ & $E_{S}=(6-30) q c$ \\
\hline 3 & Pasir berlempung & $E_{S}=(3-6) q c$ \\
\hline 4 & Pasir berlanau & $E_{S}=(1-2) q c$ \\
\hline 5 & Lempung lunak & $E_{S}=(3-8) q c$ \\
\hline
\end{tabular}

Nilai perkiraan modulus (Es) elastisitas tanah menurut Bowles dapat dilihat pada tabel 3.4.

Tabel 1.2 Nilai Perkiraan Mod. (Es) Elastisitas Tanah Menurut (Bowles, 1997)

\begin{tabular}{|c|l|c|}
\hline No & Macam Tanah & $\begin{array}{c}\text { Modulus Elastisitas } \\
\text { Tanah }\left(\mathbf{K g} / \mathbf{c m}^{\mathbf{2}}\right)\end{array}$ \\
\hline 1 & Lempung & \\
\hline & Sangat lunak & $3-30$ \\
\hline & Lunak & $20-40$ \\
\hline & Sedang & $45-90$ \\
\hline & Berpasir & $300-425$ \\
\hline 2 & Pasir \\
\hline & Berlanau & $50-200$ \\
\hline & Tidak padat & $100-250$ \\
\hline & Padat & $500-1000$ \\
\hline 3 & Pasir Dan Kerikil & \\
\hline & Padat & $800-2000$ \\
\hline & Tidak padat & $500-1400$ \\
\hline 4 & Lanau & $20-200$ \\
\hline 5 & Loses & $150-600$ \\
\hline 6 & Cadas & $1400-14000$ \\
\hline
\end{tabular}

Kohesi

Kohesi merupakan gaya tarik menarik antar partikel tanah. Bersama dengan sudut geser dalam, kohesi merupakan parameter kuat geser tanah yang menetukan ketahanan tanah terhadap deformasi akibat tegangan yang bekerja pada tanah dalam hal ini berupa gerakan lateral sesuai dengan tanah. Nilai kohesi secara empiris dapat ditentukan dari data sondir $(q c)$ yaitu sebagai berikut:

Kohesi $(c)=q c / 20$

Korelasi yang didapat dari percobaan sondir dengan biokonis, untuk 
tanah lempung nilai $\mathrm{qc}=2 \mathrm{~N}$ dan untuk pasir nilai qc $=4 \mathrm{~N}$ (Sunggono, 1995:132) Dari percobaan sondir diperoleh nilai tahanan ujung atau perlawanan ujung konus yang disebut qc.

\section{Permeabilitas}

Berdasarkan persamaan KozenyCarman, nilai permeabilitas untuk setiap layer tanah dapat dicari dengan menggunakan rumus:

$\mathrm{k}=\frac{e^{\mathrm{g}}}{1+\theta}$.

Untuk tanah yang berlapis-lapis harus dicari nilai permeabilitas untuk arah vertical dan horizontal dapat dicari dengan rumus:

$\mathrm{k}_{\mathrm{v}}=\frac{H}{\left(\frac{H_{1}}{K_{1}}\right)+\left(\frac{H_{2}}{K_{2}}\right)+\left(\frac{H_{n}}{k_{n}}\right)}$

Dimana:

$\mathrm{H}=$ Tebal lapisan $(\mathrm{cm})$

$\mathrm{E}=$ Angka pori

$\mathrm{K}=$ Koefisien permeabilitas

$\mathrm{k}_{\mathrm{v}}=$ Koef. permeabilitas arahvertikal

$\mathrm{k}_{\mathrm{h}}=$ Koef.permeabilitasarahhorizontal

\section{Pembagian Beban Horizontal Yang Bekerja Pada Tiang Pancang Kelompok}

Gaya lateral adalah gaya yang bekerja pada pile cap dengan arah horizontal.Menurut McNulty (1956) model ikatan tiang pancang dengan pile cap terdiri dari 2 type, yaitu (1) fixed and pile : tiang yang ujung atasnya tertanam $>60 \mathrm{~cm}$ pada pile cap dan free end pile

tiang yang ujung atasnya tertanam $<60 \mathrm{~cm}$ pada pile cap.

Tabel 1.3 Beban Lateral Ijin Pada Tiang Vertikal (Mcnulty,1956 dalam Hardiyatmo

\begin{tabular}{|c|c|c|c|}
\hline \multicolumn{4}{|c|}{ 2006) } \\
\hline $\begin{array}{c}\text { Ukuran } \\
\text { Tiang }\end{array}$ & $\begin{array}{l}\text { Type } \\
\text { Tiang }\end{array}$ & $\begin{array}{c}\text { Type } \\
\text { Tanah }\end{array}$ & $\begin{array}{c}\text { Beban } \\
\text { Lateral } \\
\text { Ijin } \\
(\mathbf{k g})\end{array}$ \\
\hline \multirow[t]{3}{*}{$\begin{array}{c}\text { Beton } \phi \\
40 \mathrm{~cm}\end{array}$} & \multirow{3}{*}{$\begin{array}{c}\text { Ujung } \\
\text { bebas } \\
\text { Dan } \\
\text { Ujung } \\
\text { jepit }\end{array}$} & $\begin{array}{c}\text { Pasir } \\
\text { sedang }\end{array}$ & 3178 \\
\hline & & Pasir halus & 2497 \\
\hline & & $\begin{array}{c}\text { Lempung / } \\
\text { kohesif }\end{array}$ & 2270 \\
\hline
\end{tabular}

Daya Dukung Pondasi Bor Pile Dengan Metode Elemen Hingga Menggunakan PLAXIS 2D V8.2

Daya dukung pondasi dapat ditentukan dari hasil perhitungan sondir, tujuan perhitungan daya dukung ini dipergunakan untuk menentukan kelas tanah dan juga menentukan tipe pondasi yang akan didesain. Analisis-analisis daya dukung, dilakukan dengan cara pendekatan untuk memudahkan hitungan.

Daya Dukung Pondasi Berdasarkan Data Sondir

Diantara perbedaan tes lapangan, sondir atau cone penetration test (CPT) sering kali dipertimbangkan dengan perananya dari geoteknik, CPT atau sondir ini tes yang sangat cepat, sederhana, ekonomis dan tes tersebut dapat dipercaya di lapangan dengan pengukuran terus menerus dari permukaan tanah dasar.

\section{Faktor Aman}

Untuk memperoleh kapasitas ijin tiang yang kokoh terhadap struktur, maka perlu membagi kapasitas ultimit tiang dengan factor aman tertentu.Pemilihan faktor aman (Sf)untuk perencanaan pondasi tiang (Reese \& O'Neil, 1989)menyarankan seperti tabel 3.11 (Hardiyatmo, 2008:118).

Tabel 1.4 Penggunaan Faktor Aman

Klasifikasi Struktur (Hardiyatmo, 2010:163)

\begin{tabular}{|c|c|c|c|c|}
\hline \multirow{2}{*}{$\begin{array}{c}\text { Klasifikasi } \\
\text { Struktur }\end{array}$} & \multicolumn{4}{|c|}{ Faktor Aman $(S f)$} \\
\cline { 2 - 5 } & $\begin{array}{c}\text { Kon } \\
\text { Baik }\end{array}$ & $\begin{array}{c}\text { Kon. } \\
\text { Norma } \\
\mathbf{l}\end{array}$ & $\begin{array}{c}\text { Kon. } \\
\text { Jele } \\
\text { k }\end{array}$ & $\begin{array}{c}\text { Kon.l } \\
\text { Sanga } \\
\text { t Jelek }\end{array}$ \\
\hline $\begin{array}{c}\text { Monumenta } \\
\text { Banyyyy}\end{array}$ & 2,3 & 3,0 & 3,5 & 4,0 \\
\hline Permanen & 2,0 & 2,5 & 2,8 & 3,4 \\
\hline Sementara & 1,4 & 2,0 & 2,3 & 2,8 \\
\hline
\end{tabular}

\section{Penurunan Tiang}

Pada perhitungan pondasi tiang, kapasitas izin tiang sering lebih didasarkan pada persyaratan penurunan.

\section{Defleksi Horizontal Yang Diijinkan}

Pondasi tiang harus dirancang dengan memperhitungkan beban-beban lateral atau horizontal jika tiang dipancang vertikal dan dirancang untuk mendukung 
beban horizontal yang cukup besar, seperti beban angin, tekanan tanah lateral, beban gelombang air, benturan kapal dan lainlain.

\section{Metode Elemen Hingga Menggunakan PLAXIS 2D}

Dalam dunia teknik sipil sendiri, khususnya geoteknik, dikenal program perhitungan Soil and Rock Mechanics yaitu Plaxis 2D. PLAXIS 2D merupakan program elemen hingga untuk aplikasi geoteknik dimana digunakan model model tanah untuk melakukan simulasi terhadap perilaku dari tanah.

\section{METODOLOGI PENELITIAN Lokasi Penelitian}

Dalam penelitian ini peneliti memilih pembangunan gedung mahasiswa dikawasan Universitas Islam Riau Pekanbaru yang berlokasi dijalan Kaharuddin Nasution No.113 Marpoyan Damai-Pekanbaru Riau.

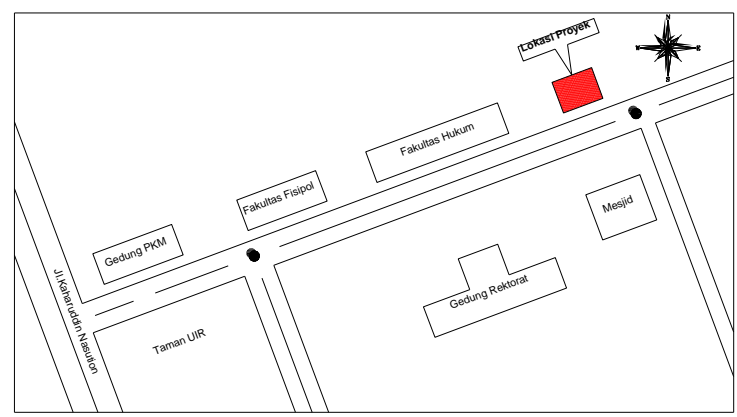

Gambar 1.4 Lokasi penelitian.

\section{Data Dan Teknis Tiang Bor}

Pondasi yang digunakan adalah pondasi jenis tiang bor (bored pile) dengan diameter $30 \mathrm{~cm}$ dan panjang tiang $12 \mathrm{~m}$. Pengerjaan pondasi dimulai pada kedalaman 1,5 m dari permukaan tanah.

Data ini diperoleh dari peneliti sebelum dengan data sebagai berikut :
1. Panjang tiang bor
$: 12 \mathrm{~m}$
2. Diameter tiang bor
: $30 \mathrm{~cm}$
3. Mutu beton
: K-225
4. Denah titik tiang bor

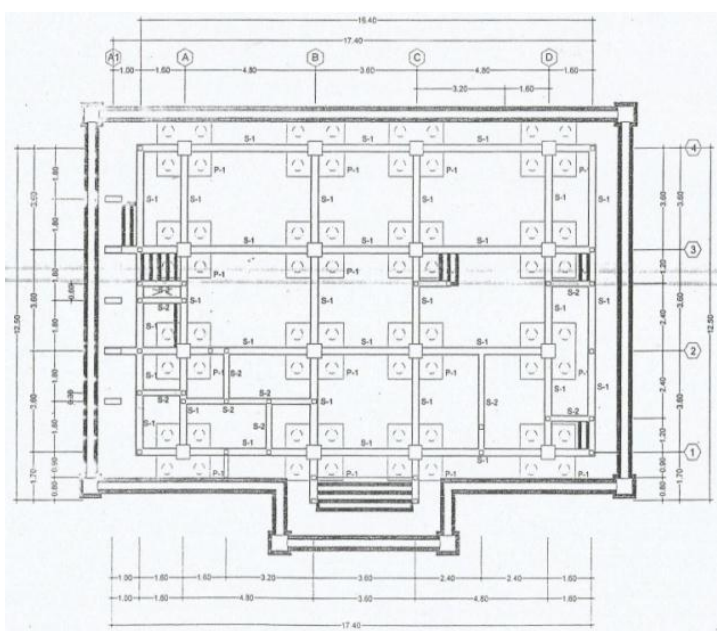

Gambar 1.5 Denah Tiang Bor

5. Detail pondasi

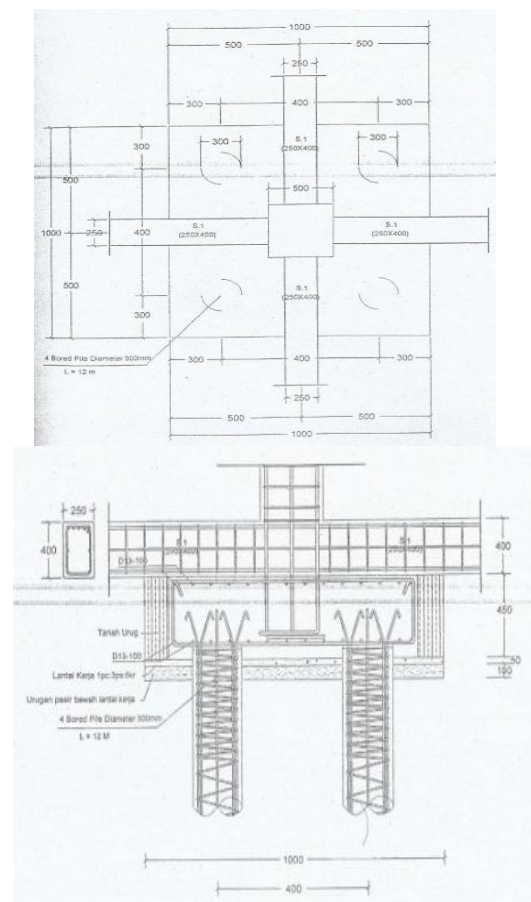

Gambar 1.6 Detail Pondasi Tiang Bor 
Tahapan Pelaksanaan Penelitian

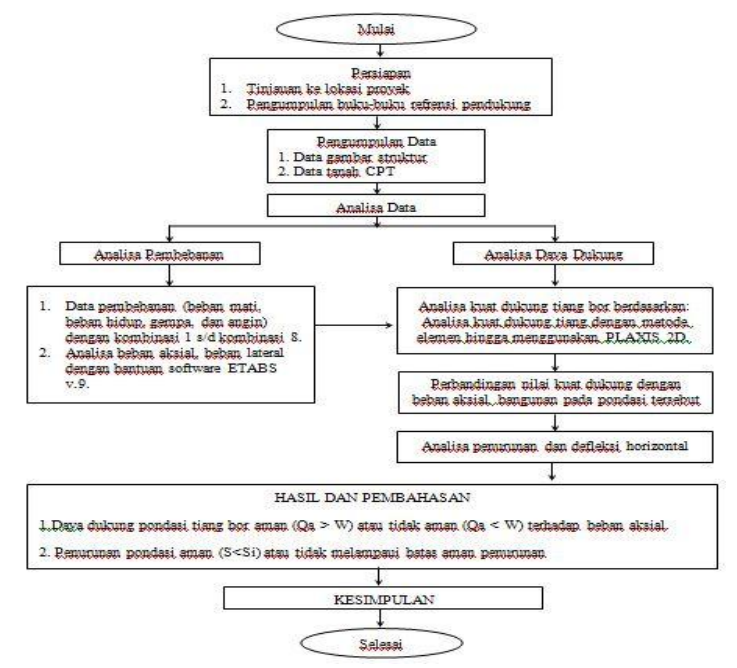

Gambar 1.7 Bagan Alir Penelitian

\section{Cara Analisis}

Cara analisis dengan cara sebagai berikut:

1. Menentukan jenis tanah dengan cara klasifikasi tanah menurut (Robertson dan Campanella, (1983)).

2. Menentukan berat isi tanah dengan caramengetahui jenis tanah dan menyesuaikan dengan tabel (John Wiley \& Sons Dalam Widya, 2011).

3. Menentukan modulus young.

4. Menentukan poisson ratio dengan cara mengetahui jenis tanah dan menyesuaikan dengan tabel (Das, 1995).

5. Menentukan sudut geser dalam dengan cara mengetahui jenis tanah dan menyesuaikan dengan tabel (Das, 1995 dan Bjerrum, 1960).

6. Menentukan kohesi.

7. Menentukan permeabilitas dengan cara mengetahui jenis tanah dan menyesuaikan dengan tabel (Das, 1995).

8. Menentukan pembebanan dengan menggunakan software ETABS v9.

9. Menentukan daya dukung aksial dan lateral dengan software PLAXIS 2D.

10. Menentukan penurunan dan defleksi horizontal dengan software PLAXIS 2D.

\section{HASIL DAN PEMBAHASAN Gambaran Umum}

Penelitian ini di lakukan pada pembangunan Gedung Mahasiswa kawasan Universitas Islam Riau Pekanbaru, yang dimana menggunakan pondasi bored pile group dengan diameter $30 \mathrm{~cm}$, kedalaman tiang masing-masing 12 $\mathrm{m}$ dari muka tanah, dengan mutu beton yang digunakan pada pondasi bored pile $\mathrm{K}-225\left(f c^{\prime}=19 \mathrm{Mpa}\right)$, dan penyelidikan tanah menggunakan data hasil cone penetration test (CPT).

\section{Hasil Klasifikasi Jenis Tanah Berdasarkan Data Sondir (CPT)}

Pengklasifikasian jenis tanah pada data sondir berguna untuk mengetahui jenis tanah yang ada pada sekitar pondasi bored pile, didalam penelitian ini klasifikasi jenis tanah pada pembangunan gedung Mahasiswa Universitas Islam Riau dapat menggunakan persamaan (3.1) dan terdapat 2 titik hasil penyondiran, data hasil klasifikasi jenis tanah pada gedung mahasiswa Universitas Islam Riau pada titik sondir S-1 di dapatkan 5 jenis tanah yaitu tanah lempung lunak, tanah lanau berlempung, tanah lanau, tanah pasir tidak padat, pasir padat dapat dilihat pada gambar 1.8:

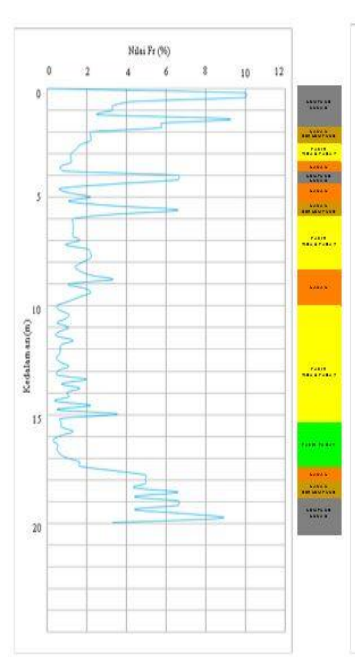

(a)

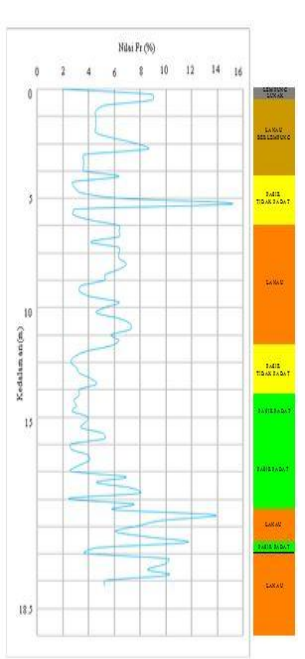

(b)
Gambar 1.8 Grafik Klarifikasi Tanah Titik Sondir 1 (a) dan Grafik Klarifikasi Tanah Titik Sondir 2 (b) 
Parameter yang diperoleh berdasarkan data penyelidikan tanah seperti grafik di atas ada 5 jenis tanah yamg didapatkan yaitu tanah lempung lunak, tanah lanau berlempung, tanah lanau, tanah pasir tidak padat, pasir padat berikut input masing-masing parameter tanah yang didapat.

Hasil Analisa Beban Bangunan Hasil Analisa Beban Aksial Bangunan Tabel 1.5 Hasil Analisa ETABS V.9 Pada Beban Aksial Paling Kritis

\begin{tabular}{|c|c|c|c|}
\hline Keterangan & $\begin{array}{c}\text { Arah } \\
\text { Gaya }\end{array}$ & As & $\begin{array}{c}\text { Beban } \\
\text { Yang } \\
\text { Bekerja } \\
\text { (kN) }\end{array}$ \\
\hline $\begin{array}{c}\text { Penelitian } \\
\text { ini }\end{array}$ & $\begin{array}{c}\text { Gaya } \\
\text { aksial }\end{array}$ & 3 - B & 344,898 \\
\hline $\begin{array}{c}\text { Peneliti } \\
\text { Deny, 2015 }\end{array}$ & $\begin{array}{c}\text { Gaya } \\
\text { aksial }\end{array}$ & 3 - C & 189,850 \\
\hline
\end{tabular}

Hasil perhitungan beban aksial dengan ditambahkan momen dan berat sendiri pile cap, dengan hasil penelitian terdahulu dapat dilihat pada tabel 1.6.

Tabel 1.6 Hasil Analisa Beban Aksial

\begin{tabular}{|c|c|c|c|c|}
\hline $\begin{array}{l}\text { Ketera } \\
\text { ngan }\end{array}$ & As & $\begin{array}{l}\text { Kom } \\
\text { binasi }\end{array}$ & $\begin{array}{c}\text { Ara } \\
\text { h } \\
\text { Gay } \\
\text { a }\end{array}$ & $\begin{array}{c}\text { Beban } \\
\text { Yang } \\
\text { Bekerja } \\
(\mathrm{kN})\end{array}$ \\
\hline $\begin{array}{l}\text { Gaya } \\
\text { aksial }\end{array}$ & $3-B$ & $\begin{array}{c}\text { Comb } \\
2 \mathrm{~A}\end{array}$ & Y & $\begin{array}{c}1259,9 \\
00\end{array}$ \\
\hline \multirow{2}{*}{$\begin{array}{l}\text { Gaya } \\
\text { lateral }\end{array}$} & \multirow{2}{*}{$3-B$} & \multirow{2}{*}{$\begin{array}{c}\text { Comb } \\
2 \mathrm{~A}\end{array}$} & $\mathrm{X}$ & 6,336 \\
\hline & & & $\mathrm{Y}$ & 4,081 \\
\hline \multirow{2}{*}{$\begin{array}{l}\text { Mome } \\
\text { n lentur }\end{array}$} & \multirow{2}{*}{$3-B$} & \multirow{2}{*}{$\begin{array}{c}\text { Comb } \\
2 \mathrm{~A}\end{array}$} & $\mathrm{X}$ & 5,808 \\
\hline & & & $Y$ & 9,491 \\
\hline
\end{tabular}

Berdasarkan dari hasil tabel 1.6 maka dapat disajikan secara grafik hasil analisa beban aksial yang bekerja pada pondasi bored pile tunggal.

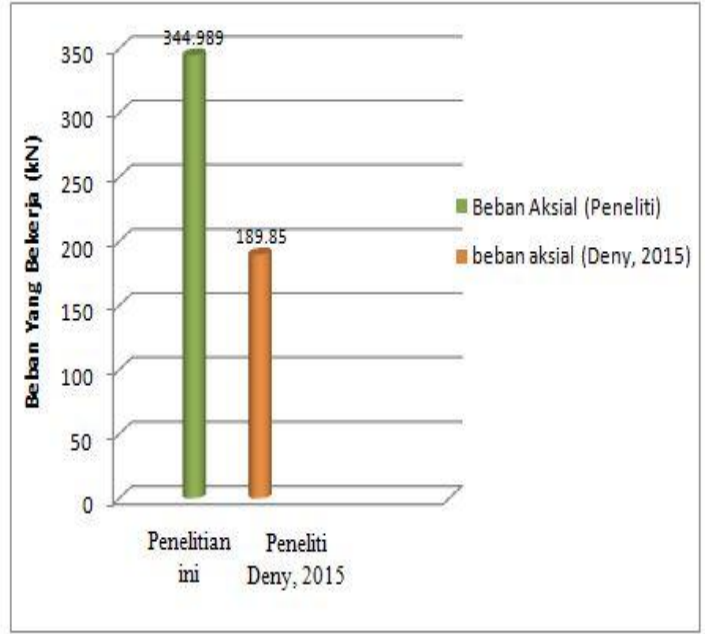

Gambar 1.9 Grafik Beban Aksial Yang Bekerja

Hasil Analisa Beban Lateral Bangunan Tabel 1.7 Hasil Analisa ETABS V.9 Pada Beban Lateral Paling Kritis

\begin{tabular}{|c|c|c|c|c|}
\hline $\begin{array}{c}\text { Keter } \\
\text { anga } \\
\mathbf{n}\end{array}$ & As & $\begin{array}{c}\text { Kom } \\
\text { binasi }\end{array}$ & $\begin{array}{c}\text { Ara } \\
\text { h } \\
\text { Gay } \\
\text { a }\end{array}$ & $\begin{array}{c}\text { Beban } \\
\text { Yang } \\
\text { Bekerja } \\
(\mathrm{kN})\end{array}$ \\
\hline $\begin{array}{c}\text { Gaya } \\
\text { aksial }\end{array}$ & $\begin{array}{l}3- \\
\text { A }\end{array}$ & $\begin{array}{c}\text { Comb } \\
5 \mathrm{~A}\end{array}$ & Y & 678,764 \\
\hline \multirow{2}{*}{$\begin{array}{l}\text { Gaya } \\
\text { lateral }\end{array}$} & \multirow{2}{*}{$\begin{array}{l}3- \\
A\end{array}$} & \multirow{2}{*}{$\begin{array}{c}\text { Comb } \\
5 \mathrm{~A}\end{array}$} & $X$ & 41,970 \\
\hline & & & $\mathrm{Y}$ & 32,504 \\
\hline \multirow{2}{*}{$\begin{array}{l}\text { Mom } \\
\text { en } \\
\text { lentur }\end{array}$} & \multirow{2}{*}{$\begin{array}{l}3- \\
\text { A }\end{array}$} & \multirow{2}{*}{$\begin{array}{c}\text { Comb } \\
5 \mathrm{~A}\end{array}$} & $\mathrm{X}$ & 9,327 \\
\hline & & & $\mathrm{Y}$ & 3,750 \\
\hline
\end{tabular}

Tabel 1.8 Hasil Analisa Beban Lateral

\begin{tabular}{|c|c|c|c|}
\hline Keterangan & $\begin{array}{c}\text { Arah } \\
\text { Gaya }\end{array}$ & As & $\begin{array}{c}\text { Beban } \\
\text { Yang } \\
\text { Bekerja } \\
\text { (kN) }\end{array}$ \\
\hline $\begin{array}{c}\text { Penelitian } \\
\text { ini }\end{array}$ & $\begin{array}{c}\text { Gaya } \\
\text { lateral }\end{array}$ & 3-A & 26,542 \\
\hline $\begin{array}{c}\text { Peneliti } \\
\text { Deny,2015 }\end{array}$ & $\begin{array}{c}\text { Gaya } \\
\text { lateral }\end{array}$ & - & - \\
\hline
\end{tabular}

Dari hasil analisa beban lateral dan setelah ditambahkan momen, berat sendiri pile capmaka didapat beban lateral maksimum pada as 3-A yaitu sebesar $26,542 \mathrm{kN}$. 
Hasil Analisa Kapasitas Kuat Dukung Pondasi Bored Pile Tunggal Hasil Analisa Kapasitas Kuat Dukung Beban Aksial

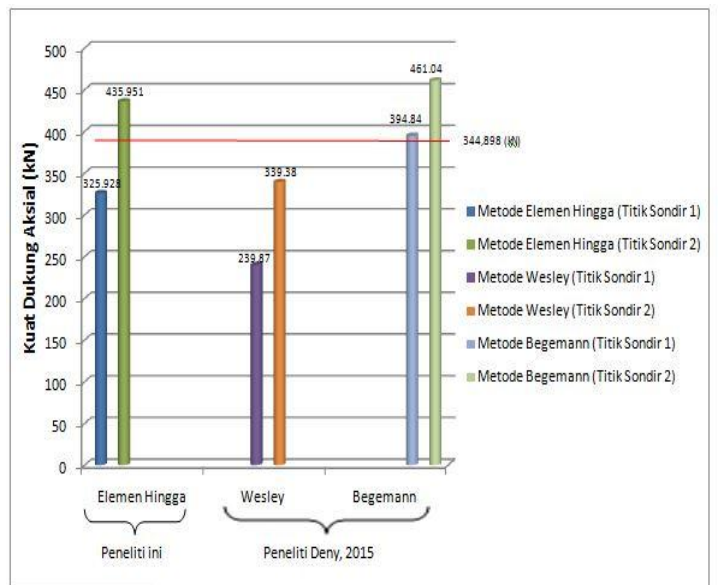

Gambar 1.10 Grafik Kuat Dukung Beban Aksial

\section{Hasil Analisa Kapasitas Kuat Dukung Beban Lateral}

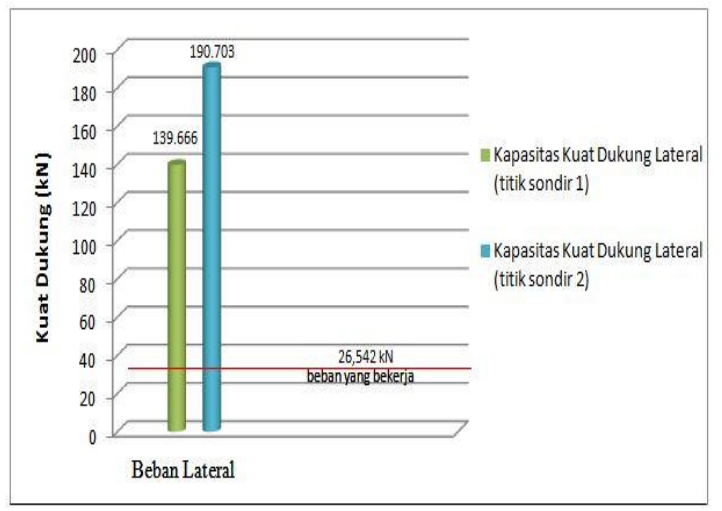

Gambar 1.11 Grafik Kuat Dukung Beban Lateral

Hasil Analisa Penurunan dan Defleksi Horizontal Pondasi Bored Pile Penurunan Pondasi Bored Pile

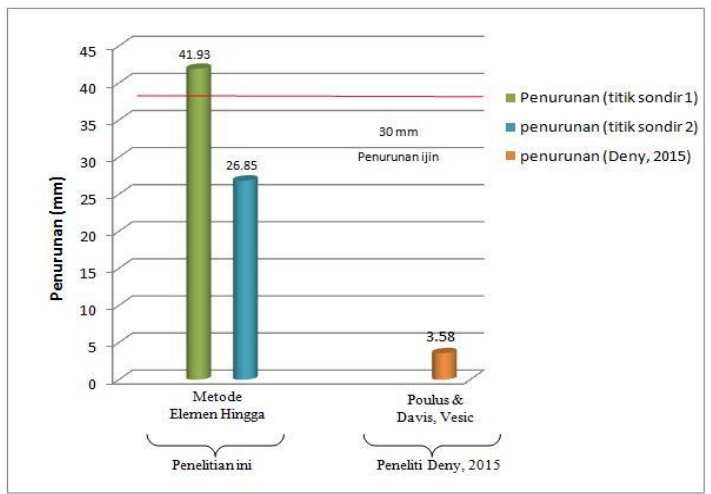

Gambar 1.12 Grafik Penurunan pondasi

\section{Defleksi Horizontal Pondasi Bored Pile}

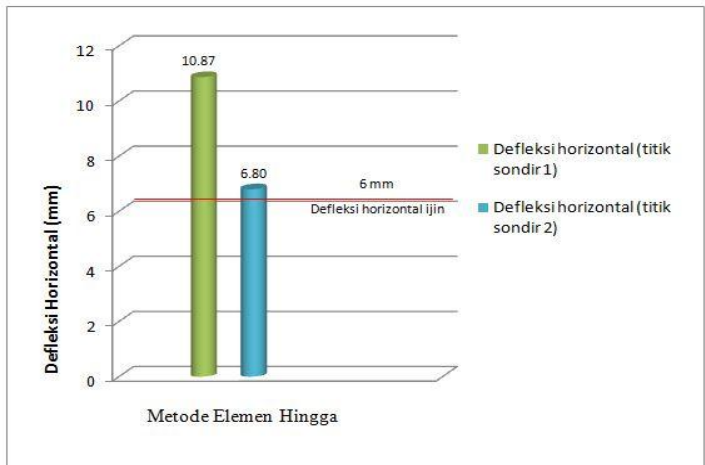

Gambar 1.13 Grafik Defleksi Horizontal Pondasi

\section{Penurunan dan Defleksi Horizontal Pondasi Bored Pile Setelah Konsolidasi}

Konsolidasi adalah suatu proses pengecilan volume secara perlahan-lahan pada tanahjenuh sempurna dengan permeabilitas rendah akibat pengaliran scbagian air pori, dengan kata lain pengertian konsolidasi adalah proses terperasnya air tanah akibatbekerjanya beban, konsolidasi dilakukan dengan metode elemen hingga menggunakan software PLAXIS 2D V8.2 setelah dilakukan analisa konsolidasi maka didapatkan hasil konsolidasi terhadap penurunan pondasi dan hasil konsolidasi terhadap defleksi horizontal seperti tabel 5.9 dibawah ini :

Tabel 1.9 Penurunan dan Defleksi Horizontal Pondasi Bored Pile Setelah Konsolidasi (Analisa)

\begin{tabular}{|l|c|c|c|c|}
\hline Metode & $\begin{array}{c}\text { Titik } \\
\text { Pondasi }\end{array}$ & Bentuk Perpindahan & $\begin{array}{c}\text { Sebelum } \\
\text { Konsolidasi } \\
(\mathbf{m m})\end{array}$ & $\begin{array}{c}\text { Sesudah } \\
\text { Konsolidasi } \\
(\mathbf{m m})\end{array}$ \\
\hline $\begin{array}{l}\text { Metode } \\
\text { Elemen } \\
\text { Hingga }\end{array}$ & As 3-B & $\begin{array}{c}\text { Penurunan } \\
\text { (Titik sondir 1) }\end{array}$ & 41,93 & 43,14 \\
\cline { 2 - 5 } & As 3-B & $\begin{array}{c}\text { Defleksi horizontal } \\
\text { (Titik sondir 1) }\end{array}$ & 10,87 & 12,27 \\
\hline $\begin{array}{l}\text { Metode } \\
\text { Elemen }\end{array}$ & As 3-A & $\begin{array}{c}\text { Penurunan } \\
\text { (Titik sondir 2) }\end{array}$ & 26,85 & 28,41 \\
\cline { 2 - 5 } Hingga & As 3-A & $\begin{array}{c}\text { Defleksi horizontal } \\
\text { (Titik sondir 2) }\end{array}$ & 6,80 & 7,74 \\
\hline
\end{tabular}

Hasil diatas menunjukan bahwa hasil dari analisa setelah dilakukan konsolidasi didapatkan hasil yang lebih besar dari sebelum dilakukannya konsolidasi. 


\section{KESIMPULAN}

Berdasarkan hasil perhitungan dan pembahasan penelitian yang telah dilakukan dapat diambil beberapa kesimpulan sebagai berikut :

1. Berdasarkan hasil analisa kapasitas daya dukung izin menggunakan metode elemen hingga menggunakan PLAXIS 2D V8.2 terhadap pondasi tiang tunggal, dimana kapasitas daya dukung aksial yang sudah dijumlahkan dengan momen dan berat sendiri pile cap didapat pada titik sondir 1 yaitu sebesar 325,928 $\mathrm{kN}$ dimana beban yang bekerja yaitu sebesar 344,898 kN maka pondasi bored pile tiang tunggal belum memenuhi syarat yang diijinkan dan pada titik sondir 2 yaitu sebesar 435,951 kN dimana beban yang bekerja yaitu sebesar $344,898 \mathrm{kN}$ maka pondasi bored pile tiang tunggal sudah memenuhi syarat yang diijinkan, untuk kapasitas daya dukung lateral yang sudah dijumlahkan dengan momen dan berat sendiri pile cap didapat pada titik sondir 1 yaitu sebesar 139,666 kN dan untuk titik sondir 2 yaitu sebesar $190,703 \mathrm{kN}$ dimana beban yang bekerja yaitu sebesar 26,542 $\mathrm{kN}$ maka pondasi bored pile tiang tunggal memenuhi syarat yang diijinkan.

2. Penurunan pondasi bored pile tunggal yang terjadi pada gedung Mahasiswa Universitas Islam Riau padatitik sondir 1 yaitu sebesar $41,93 \mathrm{~mm}$ untuk penurunan ijin yaitu $30 \mathrm{~mm}$ maka penurunan belum memenuhi syarat yang diijinkan sedangkanpada titik sondir 2 yaitu sebesar $26,85 \mathrm{~mm}$ untuk penurunan ijin yaitu sebesar $30 \mathrm{~mm}$ maka penurunan sudah memenuhi syarat yang diijinkan, sedangkan untuk defleksi horizontal yang terjadi pada titik sondir 1 yaitu sebesar 10,87 mm danpada titik sondir 2 yaitu sebesar $6,80 \mathrm{~mm}$ untukdefleksi horizontal ijin yaitu sebesar $6 \mathrm{~mm}$ maka defleksi yang terjadi belum memenuhi syarat yang diijinkan.

\section{Saran-Saran}

Dalam penulisan tugas akhir ini, penulis memiliki beberapa saran sebagai berikut :

1. Dari hasil analisa daya dukung dengan metode elemen hingga menggunakan PLAXIS 2D V8.2, sebaiknya dilakukan perbandingan dengan metode analitis lain seperti mayerhof 1976, dan lainlainnya.

2. Untuk peneliti selanjutnya yang menggunakan software PLAXIS 2D V8.2 agar menggunakan parameter tanah dari hasil Metode Borehole, agar dihasilkan model yang lebih baik.

\section{DAFTAR PUSTAKA}

Bowles, J.E., 1997, Analisis Dan Desain Pondasi, Jilid 1, Penerbit Erlangga, Jakarta.

Bowles, J.E., 1988, Analisis Dan Desain Pondasi, Jilid 1, Penerbit Erlangga, Jakarta.

Bowles, J.E., 1988, Analisis Dan Desain Pondasi, Jilid 2, Penerbit Erlangga, Jakarta.

Das, Braja M.,1995, Mekanika Tanah(Prinsip-Prinsip Rekayasa Geoteknis), Jilid 1,Penerbit, Erlangga, Jakarta.

Das, Braja M., 1984, Principles Of Foundation Engineering, PWS Engeneering,Boston.

Deny, 2015, Analisa Daya Dukung Pondasi Bored Pile Pada Gedung MahasiswaUniversitasIslam Riau, Tugas Akhir, Universitas Islam Riau.

Djatmiko, Purnomo,1993, Mekanika Tanah 1, Penerbit Kanisius, Malang.Girsang, 2009, Analisa Daya Dukung Pondasi Tiang Bor Tunggal Pada Proyek

PembangunanGedung Crystal Square Jl. Imam Bonjol No.6 Medan, Tugas Akhir, Universitas Sumatra Utara.

Hardyatmo, H.C, 2010, Analisa Dan Perancangan Pondasi II, Gadjah Mada University Press, Yogyakarta.

Hardyatmo, H.C, 2008, Teknik Pondasi 2, Jilid 4, Penerbit, Beta Offset, Yogyakarta. 
Hardyatmo, H.C, 2006, Teknik Pondasi 2, Jilid 4, Penerbit, Beta Offset, Yogyakarta.

Hardyatmo, H.C, 2002, Teknik Pondasi 2, Jilid 4, Penerbit, Beta Offset, Yogyakarta.

Harianto, 2007, Analisa Daya Dukung Pondasi Tiang Bor Menggunakan Software SHAFTI Dan Uji Beban Statis (Studi Kasus Tiang Uji TP-4 Dan TP-5 Pada Grand Indonesia) Di Jakarta, Tugas Akhir, Universitas Katolik Soegijapranata, Semarang.

Oktafiani, 2013, Analisa Daya Dukung Pondasi Tiang Pancang Pada GedungPusat KegiatanMahasiswa (PKM) Universitas Islam Riau, Tugas Akhir, Universitas Islam Riau, Pekanbaru.

Sunggono,K.H., 1995, Buku Teknik Sipil, Penerbit Nova, Bandung.

Teten, 2002, Analisa Daya Dukung Pondasi Bored Pile Gedung Bank Indonesia di Pekanbaru, Tugas Akhir, Universitas Islam Riau, Pekanbaru.

Widya, Bonifasius, 2011, Stabilitas tebing pada proyek jalan tol semarang-ungaran Sta $6+000 \quad-$ 6+250, Tugas Akhir, Universitas Diponegoro, Semarang.

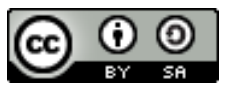

This is an open access article which means that all content is freely available without charge to the user or his/her institution. Jurnal Saintis allows the author(s) to hold the copyright without restriction. The copyright in the text of individual articles (including research articles, opinion articles, and abstracts) is the property of their respective authors distributed under the terms of the Creative Commons Attribution-ShareAlike 4.0 International License(https://creativecommons.org/licenses/by-sa/4.0/) which permits unrestricted use, distribution, and reproduction in any medium. Users are allowed to read, download, copy, distribute, search, or link to full-text articles in this journal without asking by giving appropriate credit, provide a link to the license, and indicate if changes were made. 